INGURUAK [71] | 2021 | 7-36

http://dx.doi.org/10.18543/inguruak-71-2021-art02

ISSN 0214-7912

\title{
Los contextos del linchamiento de George Floyd y los aceleradores de las protestas contra el racismo sistémico
}

\author{
The contexts of the George Floyd lynching and the accelerators of protests against \\ systemic racism
}

\author{
Lorenzo Cachón Rodríguez* \\ Universidad Complutense de Madrid
}

\begin{abstract}
RESUMEN: Tras la muerte de George Floyd el 15 de mayo de 2020 se produjeron en Estados Unidos las mayores manifestaciones (por su número, duración, extensión y participación) de su historia moderna. El artículo examina el mecanismo social (la «Violencia (policial) sistémica contra los afroamericanos») que llevó al linchamiento de Floyd y el que condujo a ese tsunami de protestas («Persistencia en la resistencia»), los otros «episodios» que actuaron como aceleradores o reactivadores de las protestas (cuatro «momentos» de Donald Trump, la violencia y militarización de la respuesta policial, otras muertes de afroamericanos a manos de la policía, y la exoneración de los policías que mataron a Breonna Taylor) y los contextos de distinta "duración» que son relevantes para comprender aquellos hechos: desde el estructural "racismo sistémico», uno de cuyos mecanismos de control racial es la «violencia (policial) sistémica contra los afroamericanos», hasta otros contextos «coyunturales» como la pandemia de la covid19, las desigualdades sociales agudizadas por la pandemia, la radicalización y crispación de los discursos políticos y sociales en el marco de la campaña electoral de noviembre de 2020, y la existencia de un movimiento como Black Lives Matter y su uso de las redes sociales como cauces de movilización. Muestra también la interrelación entre contextos y mecanismos sociales y como si el primer mecanismo está incardinado con el «racismo sistémico», el segundo se alimenta de la radicalización de los discursos y del movimiento Black Lives Matter.
\end{abstract}

Palabras clave: revuelta racial, mecanismo social, racismo sistémico, violencia policial, Black Lives Matter.

ABSTRACT: After George Floyd's death on May 15, 2020, the largest demonstrations (by number, duration, extension, and participation) in its modern history took place in the United States. The article examines the social mechanism ["Systemic (police) violence against African Americans»] that led to the lynching of Floyd and the one that led to that tsunami of protests [ Persistence in resistance»], the other "episodes» that acted as accelerators or reactivators of the protests (four «moments" of Donald Trump, the violence and militarization of the police response, other deaths of African Americans at the hands of the police, and the exoneration of the policemen who killed Breonna Taylor), and the contexts of different "duration" that are relevant to understanding those events: from structural "systemic racism", one of whose mechanisms of racial control is "systemic (police) violence against African Americans", to other "conjunctural» contexts such as the pandemic of the covid19, the social inequalities exacerbated by the pandemic, the radicalization and tension in political and social discourses in the framework of the electoral campaign in November 2020, and the existence of a movement like Black Lives Matter and its use of social networks as channels of mobilization. It also shows the interrelation between contexts and social mechanisms, and as if the first mechanism is incardinated with "systemic racism», the second feeds on the radicalization of discourses and the Black Lives Matter movement.

Keywords: racial revolt, social mechanism, systemic racism, police violence, Black Lives Matter.

\footnotetext{
* Correspondencia a/Correspondence to: Lorenzo Cachón Rodríguez. Universidad Complutense de Madrid - Icachonr@ucm.es - https://orcid. org/0000-0003-4091-7967

Cómo citar/How to cite: Cachón Rodríguez, Lorenzo (2021). "Los contextos del linchamiento de George Floyd y los aceleradores de las protestas contra el racismo sistémico»; Inguruak, 71, 7-36. (http://dx.doi.org/10.18543/inguruak-71-2021-art02).

Recibido/Received: 20 septiembre 2021; Versión final/Final version: 7 diciembre 2021.

ISSN 0214-7912 / (C) 2021 UPV/EHU
}

(c) (i) (8) Esta obra está bajo una Licencia

Creative Commons Atribución-NoComercial-SinDerivadas 4.0 Internacional 


\section{INTRODUCCIÓN: LINCHAN A GEORGE FLOYD Y SE INCENDIA ESTADOS UNIDOS}

$\mathrm{Al}$ atardecer del 25 de mayo de 2020, un afroamericano de 46 años llamado George Floyd moría en Mineápolis, Minnesota. En cuestión de días su nombre iba a ser conocido en todo el mundo. Su linchamiento seguía una pauta que se ha repetido en los últimos años en Estados Unidos: un policía (blanco) le empuja contra el suelo poniendo todo su peso corporal en su rodilla que aplasta el cuello de Floyd hasta producirle la asfixia. Lo hace durante nueve minutos y veintiséis segundos. Floyd dijo «no puedo respirar» más de veinte veces. Mientras el agente Chauvin (ya condenado por esos hechos) y otros tres agentes procedían a este moderno linchamiento, un grupo de viandantes les increpaba e intentaban, inútilmente, evitar la muerte de Floyd. Una de ellas era Darnella Frazier, una joven afroamericana de 17 años que, además de enfrentarse a los policías, sacó su teléfono móvil, grabó los hechos y los difundió inmediatamente en las redes sociales. Esa misma noche comenzaron las protestas en Mineápolis.

Las imágenes del linchamiento de Floyd resucitaron las del rostro desfigurado de Emmett Till, y las del apaleamiento de Rodney King a manos (a palos) de policías blancos en Los Ángeles en 1991. Resucitaron imágenes de algunas muertes más recientes filmadas por teléfonos móviles y difundidas en las redes sociales, como la de Michael Brown en Ferguson, Misuri, en 2014 muerto a tiros por la policía mientras levantaba las manos; la de Eric Garner en Nueva York en 2014, muerto bajo la rodilla de un policía diciendo, como Floyd, «no puedo respirar»; la de Philando Castile, muerto a tiros por la policía en 2016 en la misma ciudad en que murió Floyd mientras su novia lo transmitía en directo por Facebook.

Tras la muerte de Floyd los estadounidenses «redescubrieron el poder de la acción colectiva» (Rubin, 2020): las protestas que se han producido en Estados Unidos tras su muerte y hasta finales de 2020 son las mayores de la historia moderna en Estados Unidos, tanto por el número de manifestaciones en un día o período, como por el número de participantes y por su duración. Un auténtico histórico tsunami.

En este artículo, tras las hipótesis y los elementos teóricos, y las fuentes de datos, se expondrán las dimensiones y los rasgos de la movilización social en Estados Unidos tras la muerte de Floyd, el «episodio» de su linchamiento y un conjunto de diferentes «aceleradores» de las protestas que pueden considerarse factores causales de las mismas, y, por último, los contextos en los que se produce y sin los cuales no es posible encontrar una explicación que ayude a comprender la magnitud de la contestación y sus características. El artículo se cierra con unas conclusiones donde, además de sintetizar el resultado de esta reflexión, se pone de manifiesto la relación entre el «mecanismo causal» de las protestas y los contextos en que se han producido y se apuntan algunas líneas de posibles investigaciones futuras. 


\section{HIPÓTESIS DE PARTIDA: EL MECANISMO CAUSAL DE LAS PROTESTAS Y UN CONTEXTO QUE IMPORTA}

Tras la muerte de George Floyd ha tenido lugar el mayor ciclo de protestas en la historia de Estados Unidos. La relación causal entre el «episodio» (el linchamiento) y el resultado (las protestas) parece clara a primera vista. Pero esa evidencia necesita una mejor explicación que la intuición. Porque ni la muerte de Floyd es un hecho aislado, ni las protestas tras la muerte de un afroamericano son un hecho natural. Los dos hechos activan mecanismos sociales preexistentes. con capacidad causal para producir un resultado significativo. En el caso de la muerte de Floyd designaremos el mecanismo como «Violencia (policial) sistémica contra los afroamericanos», un instrumento del racismo sistémico. En el caso de las protestas que siguieron, el mecanismo puede denominarse como «Persistencia en la resistencia». El primero de estos mecanismos ha actuado en los numerosos casos recientes de muertes de afroamericanos a manos de la policía, algunos de ellos también filmados con teléfonos móviles y difundidos en las redes sociales. Si esos otros «episodios» (Brown y Garner en 2014, Grey en 2015; Castile en 2016 y otros muchos; véase Cazenave, 2018; Cachón 2021) no han producido un resultado similar al de la muerte de Floyd, ha sido porque el contexto histórico donde se produjeron era distinto y no había activado el mecanismo de la Resistencia (o no lo había hecho con la misma magnitud); esto muestra que «el contexto importa». E importa siempre, pero sobre todo, como ocurre aquí, cuando interactúa con los «mecanismos sociales» y les dotan de gran eficacia causal.

Esta es la hipótesis que se intentará examinar en este artículo: que las protestas que le han seguido a la muerte de Floyd han tenido una dimensión (por su número, duración, extensión, participación y características) que nunca se habían alcanzado en Estados Unidos porque el linchamiento de Floyd fue «episodio» que desveló el mecanismo social de la «violencia (policial) sistémica contra los afroamericanos», y produjo la activación del mecanismo «Persistencia en la resistencia» en unos contextos determinados que amplificaron su poder como mecanismo causal, y que se vieron potenciado además por otros «episodios» que han actuado como «aceleradores» de las protestas. El objeto del artículo es mostrar esos episodios aceleradores, explicar los contextos significativos en los que se han producido, y señalar su interrelación con los mecanismos sociales en acción.

«¿Qué pasa con un sueño diferido? / Quizás se hunde / como una carga pesada. / ¿O explota?» Estos versos de Langston Hughes en su poema «Harlem» los recordó Abdul-Jabbar (2020) cuando estallaron las protestas contra la violencia policial tras la muerte de Floyd. El explanandum de este texto es esa «explosión». Pawson (2000) pone el ejemplo de la pólvora para ilustrar cómo los resultados de los mecanismos causales dependen de los contextos en los que ocurren. La pólvora explota cuando una chispa activa su mecanismo de combustión, pero eso solo ocurre si las condiciones de la pólvora son adecuadas. En nuestro análisis hay cuatro aspectos que hay que tomar en cuenta para explicar la explosión de las protestas: la pólvora es el mecanismo causal "persistencia en la resistencia»; el detona- 
dor es el linchamiento de Floyd, seguido de otros chispazos que aceleraron o reactivaron las protestas; las condiciones de la explosión son los contextos; a ellos hay que añadir el cable que une el detonador con la pólvora: la interrelación entre los mecanismos y los contextos.

La sociología ha prestado una creciente atención a la explicación de hechos sociales basada en mecanismos causales (Merton,1964; McAdam, Tarrow y Tilly 2005 y 2008). Este creciente uso de mecanismos causales no se ha visto acompañado de una confluencia en la definición del concepto. Mahoney (2001) identifica 24 definiciones de distintas del concepto "mecanismo causal» solo en el último tercio del siglo xx. La diversidad de enfoques puede verse incluso en los artículos recogidos en un mismo libro (Hedstrom y Swedberg 1998). Hedström y Ylikoski (2010: 50-52) señalan varios rasgos comunes que interesan aquí: primero, un mecanismo se identifica por el tipo de efecto que produce; segundo, un mecanismo es una noción causal irreductible, se refiere a un proceso causal que produce el efecto de interés; y tercero, el mecanismo tiene una estructura: «cuando una explicación basada en mecanismos abre la caja negra, revela esta estructura. Convierte la caja negra en una caja transparente y hace visible cómo las entidades participantes y sus propiedades, actividades y relaciones producen el efecto de interés». Para Elster (1999: 1), «los mecanismos (sociales) son patrones causales que ocurren con frecuencia y son fácilmente reconocibles, que se desencadenan en condiciones generalmente desconocidas o con consecuencias indeterminadas». Aunque hay varios aspectos discutibles en esta definición (la frecuencia, las condiciones «desconocidas»), nos inspirará para dar una definición útil para nuestro trabajo. Por su parte, Tilly distingue tres tipos de mecanismo sociales: ambientales, cognitivos y relacionales. Y define estos últimos como los que «alteran las conexiones entre personas, grupos y redes interpersonales» (Tilly, 2001: 24).

Para el análisis de las protestas tras la muerte de Floyd, entenderemos que un mecanismo social (relacional) son pautas reconocibles de comportamiento de los actores que se producen en determinadas circunstancias y que tienden a producir efectos relevantes en otros actores y en la sociedad. Al "mecanismo social» causal que interviene en la muerte de Floyd, podemos denominarlo «Violencia (policial) sistémica contra los afroamericanos». Y al que conduce al tsunami de protestas como «Persistencia en la Resistencia».

Cazenave (2018) ha expuesto cómo los homicidios reiterados y desproporcionados de afroamericanos a manos de policías y de supremacistas blancos actuando como «vigilantes» resultan de un mecanismo social que llama «violencia policial y de los vigilantes». Este mecanismo forma parte del "racismo sistémico» (Feagin y Feagin, 1978; Feagin, 2006) en Estados Unidos. Y si el racismo sistémico es «una estructura y procesos sociales grandes, altamente institucionalizados y duraderos» al servicio del control racial (como antes lo fueron la esclavitud o el Jim Crow), la «violencia policial y de los vigilantes» es uno de los mecanis-mos sociales «más pequeño, menos institucionalizado y duradero» (Cazenave, 2018: 74) que despliegan los efectos de aquel. 
Los negros han resistido activamente a esta violencia racial desde la época de la esclavitud, respondiendo con protestas y con movimientos como el de los derechos civiles en la época del Jim Crow (Morris, 1984). Así hay que entender el nacimiento de \#BlackLivesMatter como «una continuación de movimientos sociales pasados, pero innovador por derecho propio» (Nummi et al., 2019: 1043). Para comprender la dimensión que tuvieron las protestas en 2020 hay que tener en cuenta además lo que Mayer y Tarrow (2018) han llamado «la resistencia» que se produjo tras la llegada de Trump a la presidencia y que se convirtió en un ciclo de contención que es «comparable al que experimentaron los estadounidenses durante el período de los derechos civiles y el movimiento contra la Guerra de Vietnam» (Tarrow y Meyer, 2018: 3). Esa movilización tuvo un rasgo que Fisher y Jasny (2019) califican como la "persistencia en la resistencia»: muchos ciudadanos participaban en todo tipo de acciones anti-Trump, fuera la marcha de las mujeres, por el cambio climático o por el control de las armas de fuego. O contra la violencia policial. Utilizaremos ese concepto de "persistencia en la resistencia" para describir el mecanismo que se pone en marcha tras la muerte de Floyd en un doble sentido: para expresar la persistencia de las luchas de los negros contra la violencia estructural que se produce contra ellos, ahora liderada por Black Lives Matter, y también para recoger la idea que expresan Fisher y Jasny de que «la resistencia» antitrumpista se adhiere a diversas causas progresistas.

El mecanismo social (la pólvora) necesita una chipa para desatar su poder explosivo. Tilly (2001: 26) señala que «los episodios adquieren a veces un significado social porque los participantes u observadores construyen nombres, límites e historias que les corresponden»; uno de los problemas del investigador es explicar cómo algunos episodios se convierten en «significados políticamente significativos». Los «episodios» relevantes pueden ser inicial (como el linchamiento de Floyd) o subsiguientes, que actúan como «aceleradores» bien porque dan impulso a la reacción ya desencadenada del mecanismo («persistencia en la resistencia») o bien porque levantan otras reacciones que coadyuban a multiplicar sus efectos.

La acción del episodio sobre el mecanismo, sólo produce efecto si se da en un contexto habilitante o favorable. Es el «It depends» (Tilly y Goodin (2006: 6): «en respuesta a cada gran pregunta de la ciencia política, respondemos 'Depende'. Las respuestas válidas dependen del contexto en el que se desarrollen los procesos políticos estudiados». Nuestro caso permite mostrar cómo «las regularidades de los movimientos sociales dependen en gran medida de sus contextos históricos» (Tilly, 2006: 433). Por esta razón Pawson (2000: 296) llega a calificar el «contexto» como «concepto-pareja» de mecanismo social. Pero, como señala Ancelovici (2021: 126-127), «en muchos aspectos, el "contexto” es ambiguo y vago. Ambiguo porque carece de un significado claro y vago porque carece de límites claros (...). Independientemente de la dimensión que decidamos enfatizar, asumimos que tal énfasis es necesario para comprender qué está pasando. De ello se desprende que "contextualizar“ implica proporcionar suficiente información de fondo para comprender el significado de un evento o fenómeno dado». 
Para los efectos de este artículo es útil la definición de «contexto» que proporcionan Falleti y Lynch (2009: 1152): «definimos el contexto de manera amplia, como los aspectos relevantes de un escenario (analítico, temporal, espacial o institucional) en el que un conjunto de condiciones iniciales conduce (en términos probabilísticos) a un resultado de alcance y significado definidos a través de un mecanismo causal específico o un conjunto de mecanismos causales (...). De esta definición se deduce que una explicación causal requiere que el analista especifique el mecanismo causal operativo y delinee los aspectos relevantes del entorno, es decir, aquellos que permiten que el mecanismo produzca el resultado» (los subrayados son nuestros).

En los últimos años se viene prestando una atención creciente a los contextos de la acción colectiva; es oportuno que sea así porque las cuestiones del «contexto» están vinculadas al estatus mismo de la explicación en las ciencias sociales (Siméant-Germanos, 2021). Pero esos contextos relevantes no pueden limitarse a los «grandes contextos» (véase Goodin y Tilly, 2006), como «la historia», «la economía», etc. Se necesita «un enfoque más contextualizado históricamente de los movimientos sociales» (Siméant-Germanos, 2021). que afronte una explicación comprensiva de las consecuencias que tienen la interacción de determinado mecanismo social con determinados contextos históricos. Los contextos importan porque dan forma concreta a cómo ocurren los procesos sociales y políticos (Tilly y Goodin, 2006: 6). Los contextos importan porque, «si los mecanismos causales no estén contextualizados de manera apropiada, corremos el riesgo de hacer inferencias causales erróneas» (Falleti y Lynch, 2009: 1144). Los contextos importan, pero es la investigación aplicada, practicada como sociología histórica, la que debe mostrar por qué y de qué modo son relevantes los contextos.

Para ello convendría diferencias los contextos (relevantes) en diversas capas; "capas» diferenciables por su distinta «duración». Y, siguiendo a Braudel (1968), se podrían distinguir tres duraciones: la episódica, la coyuntural, y la estructural o de «larga duración». Cuestión clave es desvelar cómo esos contextos específicos de «duraciones» distintas interaccionan con los mecanismos sociales porque eso es lo que los hace relevantes, lo que les da "derecho» a entrar en la explicación. Se podría decir que esta interacción es el cable que conecta los contextos con el «episodio" (o episodios) y el mecanismo social. La investigación debería mostrar cómo se produce esa interacción porque «lo que determina el resultado es la interacción entre el mecanismo y el contexto» (Falleti y Lynch, 2009: 1151).

\section{FUENTES}

La fuente de datos de referencia para seguir el número de manifestaciones en Estados Unidos es el US Crisis Monitor. Es un proyecto conjunto del Armed Conflict Location \& Event Data Project y del Bridging Divides Initiative de la Universidad de Princeton que elabora datos diarios sobre la violencia política y las manifestaciones en todo el país. Sus 
datos distinguen entre "protestas» (protests) y «revueltas» (riots). Las protestas son definidas como manifestaciones públicas en la que los participantes no se involucran en actos de violencia, aunque pueda haberse utilizado la violencia contra ellos (por parte de la policía o de agentes privados). Las revueltas (o disturbios) son eventos violentos en los que manifestantes o multitudes participan en actos perturbadores, incluidos, entre otros, el lanzamiento de piedras u objetos, la destrucción de propiedades, etc.; pueden tener como objetivo a otras personas, propiedades, empresas, otros grupos de disturbios o actores armados. La base de datos actualiza cada día el listado de manifestaciones que se producen en Estados Unidos indicando, entre otras informaciones, fecha, tipo de evento, actor involucrado, lugar y fuente de la información. A partir de esos datos se han elaborado los cuadros que se presentan en el epígrafe siguiente, seleccionando solo las manifestaciones (protestas o revueltas) donde el actor implicado ha sido el movimiento Black Lives Matter.

En otros epígrafes se utilizarán otras fuentes secundarias de datos, especialmente algunas encuestas de centros de investigación para evaluar el número de participantes en las protestas.

\section{4. ¿QUÉ PASÓ TRAS LA MUERTE DE FLOYD? LA MAYOR REVUELTA DE LA HISTORIA DE ESTADOS UNIDOS}

Lo que ocurrió tras el linchamiento de Floyd fue la explosión por el sueño diferido de que hablaba Hughes. Un tsunami de furia y sed de justicia en el que participaron entre un $6 \%$ y un $10 \%$ de la población estadounidense en cerca de 10.000 manifestaciones a lo largo del segundo semestre de 2020 y a lo ancho de todo Estados Unidos. Nunca había tenido lugar un levantamiento popular semejante.

Entre el 25 de mayo, fecha de la muerte de Floyd, y finales de 2020, el US Crisis Monitor registró 9.520 manifestaciones ligadas al Black Lives Matter, que tuvieron lugar en los 50 estados del país y en unas 2.500 localidades. 598 de estas manifestaciones fueron violentas (véase Cuadro 1). Solo en las tres primeras semanas se produjeron 5.803 manifestaciones; de ellas, 368 tuvieron carácter violento. El mayor número de manifestaciones diarias tuvo lugar el sábado 6 de junio de 2020: de las 683 manifestaciones de ese día, solo 8 fueron violentas.

El kilómetro 0 de las protestas por la muerte de George Floyd no lo registra el US Crisis Monitor. Porque las protestas comenzaron cuando varios viandantes se enfrentaron a los policías mientras el agente Chauvin mantenía su rodilla sobre el cuello de un agonizante Floyd. Una de las manifestantes, además, grababa el linchamiento con su móvil. Y luego comenzaron protestas en el área de Mineápolis donde habían tenido lugar los hechos. 
Cuadro 1. Evolución de las manifestaciones (protestas y revueltas) tras la muerte de Floyd

\begin{tabular}{|c|c|c|c|c|c|c|}
\hline Mes & Días & $\begin{array}{l}\mathrm{N} .{ }^{\circ} \mathrm{de} \\
\text { semana }\end{array}$ & $\begin{array}{l}\text { Número total de } \\
\text { manifestaciones }\end{array}$ & Protestas & Revueltas & $\begin{array}{c}\% \text { revueltas } \\
\text { sobre total }\end{array}$ \\
\hline Mayo & $25-31$ & 1 & 1.217 & 980 & 237 & 19,5 \\
\hline \multirow{4}{*}{ Junio } & $1-7$ & 2 & 3.342 & 3.231 & 111 & 3,3 \\
\hline & $8-14$ & 3 & 1.246 & 1.226 & 20 & 1,6 \\
\hline & $15-21$ & 4 & 648 & 625 & 23 & 3,5 \\
\hline & $22-28$ & 5 & 419 & 399 & 20 & 4,8 \\
\hline \multirow{5}{*}{ Julio } & $29-5$ & 6 & 298 & 277 & 21 & 7,0 \\
\hline & $6-12$ & 7 & 185 & 178 & 7 & 3,8 \\
\hline & $13-19$ & 8 & 153 & 140 & 13 & 8,5 \\
\hline & $20-26$ & 9 & 178 & 157 & 21 & 11,8 \\
\hline & $27-2$ & 10 & 145 & 136 & 9 & 6,2 \\
\hline \multirow{4}{*}{ Agosto } & $3-9$ & 11 & 96 & 81 & 15 & 15,6 \\
\hline & $10-16$ & 12 & 83 & 71 & 12 & 14,5 \\
\hline & $17-23$ & 13 & 108 & 100 & 8 & 7,4 \\
\hline & $24-30$ & 14 & 288 & 262 & 26 & 9,0 \\
\hline \multirow{4}{*}{ Septiembre } & $31-6$ & 15 & 153 & 143 & 10 & 6,5 \\
\hline & $7-13$ & 16 & 99 & 98 & 1 & 1,0 \\
\hline & $14-20$ & 17 & 73 & 71 & 2 & 2,7 \\
\hline & $21-27$ & 18 & 267 & 247 & 20 & 7,5 \\
\hline Octubre & $280-1 \mathrm{~N}$ & $19-23$ & 296 & 286 & 10 & 3,44 \\
\hline Noviembre & $2 \mathrm{~N}-29 \mathrm{~N}$ & $24-27$ & 139 & 129 & 10 & 7,2 \\
\hline Diciembre & $30 \mathrm{~N}-3 \mathrm{E}$ & $28-32$ & 100 & 96 & 4 & 4,0 \\
\hline Total & & & 9.520 & 8.922 & 598 & 6,3 \\
\hline
\end{tabular}

Fuente: elaboración propia a partir de los datos del US Crisis Monitor.

El martes 26 de mayo se difundió el vídeo del linchamiento en las redes sociales. Esa misma tarde cientos de manifestantes llenaron las calles de Mineápolis; lo que empezó pacíficamente, siguió con una explosión de rabia y violencia cuando algunos manifestantes atacaron y quemaron vehículos policiales y se dirigieron a la comisaría de Policía. Al día siguiente el número de manifestaciones se duplicó. En Mineápolis, miles de personas salieron a las calles; comenzaron pacíficamente, pero se volvieron caóticas cuando la policía disparó balas de goma; algunos manifestantes incendiaron edificios, y una persona murió por los disparos del dueño de una tienda. No es el único muerto de ese día: otros manifestantes murieron en Misuri y en Illinois. El jueves ya hubo cincuenta manifestaciones. La prensa señaló que «las protestas sobre la muerte de George Floyd se extienden por todo Estados Unidos» (New York Times, 29 de mayo). El fenómeno entró en una fase 
cuantitativa distinta: dejó de ser local, dejó de ser de los grupos más activos, y comenzó a extenderse como una mancha de aceite por todo el territorio. El presidente Trump llamó «matones» a los manifestantes y lo remató diciendo que «cuando comienza el saqueo, comienza el tiroteo». La respuesta a estas provocaciones llegó el viernes 29: las manifestaciones se triplicaron en un solo día y hubo más de 150 por todo el país; 35 de ellas violentas.

Y así llegó el primer fin de semana tras la muerte de Floyd. Entre el sábado y el domingo 30-31 de mayo se produjeron casi mil manifestaciones, de ellas unas 180 violentas. La sensación de caos se apoderó del país. La Guardia Nacional se desplegó en dos docenas de estados para ayudar a los departamentos de policía desbordados, y los alcaldes declararon toques de queda en decenas de ciudades. Las protestas del sábado batieron el récord de manifestaciones diarias en Estados Unidos, un récord que solo durará un día porque será superado el domingo siguiente. Hubo varios muertos y decenas de heridos. Ese fin de semana se puso de manifiesto «el poder destructivo de la desesperación» (Blow, 2020).

Pero las revueltas no habían hecho más que empezar. La semana siguiente siguieron creciendo y esa segunda semana se convirtió en la de mayor número de protestas en la historia de Estados Unidos. En esa segunda semana, el movimiento ciudadano contra la violencia policial y por la justicia racial alcanzó el nivel de levantamiento popular: entre el 1 y el 7 de junio tuvieron lugar 3.342 manifestaciones ligadas a BLM, una cifra sin precedentes; y de ellas, solo 111 tuvieron un carácter violento (véase Cuadro 2). Esas manifestaciones culminaron con las 683 del sábado día 6 de junio. Ese día marca el récord de manifestaciones en un solo día en Estados Unidos (por encima de las 653 que tuvieron lugar en la Marcha de las Mujeres de enero de 2017). Aquellos días se celebraron los funerales de Floyd. A partir ese día, el número de manifestaciones comenzó a descender, aunque repuntara durante el fin de semana siguiente como reacción a la muerte de Brooks el día 12 de junio. En total, en las tres primeras semanas de movilizaciones, tuvieron lugar más de 5.800 manifestaciones, un $6 \%$ de ellas con carácter violento.

Desde el impresionante récord de protestas que tuvieron lugar en la segunda semana, las protestas fueron descendiendo. Pero hay que resaltar el hecho extraordinario de la duración de las protestas. Porque, aunque hayan descendido desde las 5.481 que tuvieron lugar en junio, a las 550 en septiembre, son cuatro meses continuados de protestas ligados a una misma motivación y con el mismo actor fundamental. Y, aunque en menor cuantía, han seguido en los tres meses siguientes. Nunca se habían mantenido durante tanto tiempo manifestaciones por un mismo motivo en Estados Unidos. Por eso se puede hablar de una (gran) movilización permanente. Lo que es extraordinario porque en «Estados Unidos rara vez tienen las protestas esta combinación de tamaño, intensidad y frecuencia; suele haber grandes protestas o protestas sostenidas, pero no ambas» (Putnam et al., 2020). 
Cuadro 2. Evolución de las manifestaciones en las tres primeras semanas tras la muerte de Floyd

\begin{tabular}{|c|c|c|c|c|c|}
\hline Días & Fechas & $\begin{array}{l}\text { Número total de } \\
\text { manifestaciones }\end{array}$ & Protestas & Revueltas & $\begin{array}{c}\% \text { revueltas } \\
\text { sobre total }\end{array}$ \\
\hline 1 & lunes 25 de mayo & 1 & 1 & 0 & 0,0 \\
\hline 2 & martes 26 de mayo & 9 & 7 & 2 & 22,2 \\
\hline 3 & miércoles 27 de mayo & 16 & 14 & 2 & 12,5 \\
\hline 4 & jueves 28 de mayo & 50 & 35 & 15 & 30,0 \\
\hline 5 & viernes 29 de mayo & 153 & 118 & 35 & 22,9 \\
\hline 6 & sábado 30 de mayo & 441 & 350 & 91 & 20,6 \\
\hline 7 & domingo 31 de mayo & 547 & 455 & 92 & 16,8 \\
\hline 8 & lunes 1 de junio & 457 & 402 & 55 & 12,0 \\
\hline 9 & martes 2 de junio & 489 & 456 & 33 & 6,7 \\
\hline 10 & miércoles 3 de junio & 460 & 455 & 5 & 1,1 \\
\hline 11 & jueves 4 de junio & 406 & 404 & 2 & 0,5 \\
\hline 12 & viernes 5 de junio & 382 & 377 & 5 & 1,3 \\
\hline 13 & sábado 6 de junio & 683 & 675 & 8 & 1,2 \\
\hline 14 & domingo 7 de junio & 465 & 462 & 3 & 0,6 \\
\hline 15 & lunes 8 de junio & 205 & 205 & 0 & 0,0 \\
\hline 16 & martes 9 de junio & 133 & 132 & 1 & 0,8 \\
\hline 17 & miércoles 10 de junio & 111 & 106 & 5 & 4,5 \\
\hline 18 & jueves 11 de junio & 149 & 145 & 4 & 2,7 \\
\hline 19 & viernes 12 de junio & 169 & 167 & 2 & 1,2 \\
\hline 20 & sábado 13 de junio & 290 & 285 & 5 & 1,7 \\
\hline 21 & domingo 14 de junio & 189 & 186 & 3 & 1,6 \\
\hline & TOTAL 25M-14J & 5.805 & 5.437 & 368 & 6,3 \\
\hline
\end{tabular}

Fuente: elaboración propia a partir de los datos del US Crisis Monitor.

Pero ha habido tres rebotes, dos de ellos importantes cuantitativamente, ligados a episodios concretos que sirvieron como aceleradores. El primero tuvo lugar en la novena semana cuando las tensiones en Portland llevaron al presidente Trump a hacer una compaña especial contra los manifestantes con anuncios en las televisiones con el lema «Ley y orden». La respuesta fue un aumento relevante de las protestas. El segundo tuvo lugar a mediados de agosto a primeros de septiembre y estuvo ligado a (las imágenes de) los siete disparos por la espalda que dejaron paralítico a Jacob Blake en Kenosha (Wisconsin) el 23 de agosto, seguidas de las muertes de Dijon Kizzee (31 de agosto) y Deon Kay (2 de septiembre), y la publicación el 2 de septiembre del vídeo con la muerte de Daniel T. Prude (que había tenido lugar en marzo). Estos hechos dieron un impulso notable al levantamiento que ya había comenzado a entrar en una fase desaceleración. La tercera reactivación se 
produjo la última semana de septiembre, cuando se hizo pública la decisión del gran jurado de no inculpar a ninguno de los policías que intervinieron en la muerte de Breonna Taylor y se conocieron mejor las circunstancias de su muerte el 13 de marzo. En estos momentos de relanzamientos de las protestas, también aumentaron el número de revueltas violentas.

Pero además del número de manifestaciones, de marcar el récord en un solo día, y de su duración, hay que recordar otro hecho insólito: su extensión geográfica. Porque hubo numerosas protestas en los cincuenta estados estadounidenses y en el Distrito de Columbia, aunque estuviesen repartidas de modo desigual por el territorio. En California tuvieron lugar más de 1.000 manifestaciones y en el estado de Nueva York unas 600; en otros quince estados se han producido más de 250 manifestaciones.

Hay otro hecho que hace extraordinario este levantamiento popular: el número de participantes. Nunca había habido tanta gente manifestándose en las calles de Estados Unidos por el mismo motivo. El 21 de enero de 2017, al día siguiente de la inauguración de la presidencia Trump, tuvo lugar la «Marcha de las mujeres» en Washington D. C. y otras 652 ciudades. El Washington Post (7 de febrero de 2017) calculó que participaron entre 3,3 y 5,2 millones de personas. Solo las movilizaciones contra la guerra de Vietnam al final de los sesenta se acercaría a esas cifras. Pero las protestas contra la violencia policial tras la muerte de George Floyd han superado esas marcas. Las protestas del movimiento por los derechos civiles de los años sesenta, que tanto impacto tuvieron y que tantas imágenes perdurables han dejado en la memoria colectiva, fueron relativamente pequeñas en número de participantes: quizás cientos de miles de personas, pero no millones.

En las manifestaciones tras la muerte de Floyd han participado un número récord de personas. A mediados de junio cuatro centros de investigación hicieron encuestas para conocer el número de participantes. Los resultados señalan un máximo de 26 millones de personas, que supone el 10\% de la población estadounidense (según Kaiser Family Foundation), y un mínimo de 15 millones, el 6\% de la población (según Pew Research Center); en medio quedan las estimaciones de Civis Analytics, con 23 millones (el $9 \%$ de la población), y N.O.R.C., con 18 millones (el 7\% de la población). Beal Caren, un investigador de los movimientos sociales decía: «Nunca había visto autoinformes de participación en protestas tan altos para un tema específico durante un período tan corto" (Buchanan et al., 2020). Estos datos se refieren solo a las primeras semanas del levantamiento popular; en esas semanas se produjeron el $60 \%$ de todas las manifestaciones del año y, probablemente, las personas que participaron en manifestaciones posteriores ya habían estado en las de estos primeros días.

Aunque, por una parte, las cifras no nos señalen en cuántas manifestaciones ha participado cada persona y, por otra, pudieran hacer una sobreestimación por cierta tendencia a mostrarse solidario en plena movilización nacional contra la violencia policial y ante el re- 
chazo que producen las imágenes de la muerte de Floyd, las estimaciones del número de personas que han participado en las protestas son tan altas y por ello tan relevantes que hay que recordar la teoría del «3,5\%», que señala que las protestas para derrocar a líderes gubernamentales suelen tener éxito cuando logran involucrar al 3,5\% de la población (Chenoweth, 2020).

Esa multitud de ciudadanos protestando en 2020 tiene una característica notable: su diversidad. Muchos de ellos eran jóvenes afroamericanos, mujeres y varones, como venía ocurriendo en las protestas de BLM. Pero ahora había una presencia masiva de personas blancas, además de latinas y de origen asiático. La mayor parte de los blancos apoyaron el movimiento de derechos civiles en los años sesenta, pero pocos salieron a la calle a defenderlo. En 2020 la comunidad negra se ha visto acompañada de blancos y latinos y nativos y asiáticos que gritaban con ellos «no puedo respirar». Según la encuesta de CIVIS del 12-19 de junio, la media de participación en las protestas era del 8,6\% de la población; en el caso de los afroamericanos ascendía al 16\%, seguido del 12\% de los nativos americanos, el $11 \%$ de los latinos y el $7 \%$ de los blancos.

El levantamiento popular no solo se ha producido en forma de manifestaciones. CIVIS (2020) muestra otros tipos de acción colectiva sobre todo en las cuatro primeras semanas: el 19\% de la población estadounidense compartió artículos en las redes sociales; el $9 \%$ boicoteó productos por razones políticas; el $8 \%$ escribió a sus representantes políticos; el 17\% firmó peticiones; el $9 \%$ dio dinero para campañas electorales; el 7\% puso un cartel ante su puerta; el $5 \%$ fue a alguna reunión política; y el 4,5\% hizo trabajo voluntario para un candidato. En conjunto, el $43 \%$ de la población llevó a cabo alguna o varias de estas acciones, y así lo hicieron el $74 \%$ de los negros y el $37 \%$ de los blancos.

La magnitud de las protestas de 2020 no se han traducido en un número de muertes comparable al de las protestas de los años sesenta (por ejemplo, en Los Ángeles 1992 murieron más de 60 personas), ni a la destrucción provocada en alguna de aquellas revueltas, ni en número de detenciones (por ejemplo, en las revueltas que siguieron a la bomba arrojada contra una iglesia negra en Birmingham, Alabama, fueron detenidos unos 15.000 activistas).

Una frase repetida mucho por activistas y analistas durante las protestas fue «Esta vez es diferente». Era la sensación de que lo que estaban haciendo, a lo que estaban asistiendo, era algo que no había pasado en la historia reciente de Estados Unidos. Gianna, la hija pequeña de Floyd, lo dijo en una manifestación: «Mi papá ha cambiado el mundo». Hay que intentar comprender por qué la muerte de su padre ha tenido consecuencias que no tuvieron las muertes anteriores de otros muchos negros a manos de la policía. 


\section{EL «EPISODIO» DEL LINCHAMIENTO DE FLOYD Y LOS ACELERADORES DE LAS PROTESTAS}

No hay duda de que la chispa, el "episodio» que hizo explotar las revueltas fue la muerte de George Floyd el día 25 de mayo en Mineápolis y el video de Darnella Frazier difundido ese mismo día a través de Facebook. La muerte de Floyd es un acto del mecanismo de «violencia (policial) contra los afroamericanos» que encontró inmediata respuesta en la activación de otro mecanismo: la "persistencia de la resistencia». Siguiendo una pauta habitual, las revueltas comenzaron en la misma ciudad donde murió Floyd y lo hicieron con gran fuerza (y violencia). Williamson et al. (2018) han mostrado como desde 2013 en que aparece el movimiento Black Lives Matter (BLM) es más probable que las protestas ligadas a BLM tengan lugar en localidades donde la policía ha matado anteriormente a (más) personas negras.

A ese «episodio» siguieron otros que aceleraron o reactivaron las protestas. Entre los aceleradores hay que incluir diversos «momentos Trump» y también la militarización de la respuesta a las revueltas; entre los episodios que reactivaron las protestas hay que incluir, de una parte, la muerte de Rayshard Brooks en Atlanta (2 de junio), el tiroteo contra Jacob Blake en Kenosha (23 de agosto); y video de la muerte de Daniel Prude (conocido el 2 de septiembre), y de otra, la exoneración de los policías que mataron a Breonna Taylor (septiembre). Sin estos episodios aceleradores o reactivadores no se puede entender la amplitud y la duración de las protestas.

Los «momentos Trump» han sido el factor acelerador clave, por el componente de resistencia antitrumpista que tuvieron las revueltas. Su papel ha sido el de un bombero pirómano porque sus provocaciones contra los manifestantes han sido numerosísimas y con una gran carga explosiva. El entonces presidente Trump se mojó con gran empeño en todos los charcos. Y los manifestantes respondieron con intensidad a esas provocaciones. Se podría pensar que eso era un «resultado no querido» de sus acciones (Merton, 1964). Pero mostraremos como esa aprente espontaneidad del presidente era una estrategia electoral pensada. Aunque son numerosísimos sus gestos, declaraciones y acciones provocadoras, nos centraremos en cuatro «momentos». El primero tuvo lugar el viernes 29 de mayo y dio alas a las explosiones de protestas el primer fin de semana tras la muerte de Floyd. Ese día Trump publicó dos tuits encadenados. En el primero atacaba a la «izquierda radical» y en el segundo dice: «... Estos MATONES están deshonrando la memoria de George Floyd, y no permitiré que eso suceda (...). Cualquier dificultad y asumiremos el control, porque cuando comienzan los saqueos, comienzan los disparos (When the looting starts, the shooting starts) ¡Gracias!». La provocación era tan notable que, por primera vez, la empresa Twitter restringió el acceso al tuit porque "glorificaba la violencia». La expresión "When the looting starts, the shooting starts» tiene históricas raíces de racismo antinegro (Sprunt, 2020).

Un segundo relevante «momento Trump» se produjo ese mismo día. Una manifestación alrededor de la Casa Blanca hizo que el Servicio Secreto llevara a Trump al bunker de segu- 
ridad. Al salir del bunker, estalló en Twitter con insultos a los manifestantes y sugirió a sus partidarios que se enfrentaran con ellos: «Tengo entendido que esta noche es NOCHE MAGA EN LA CASA BLANCA???» (sic) (MAGA es la abreviatura de "Make America Great Again»). Y al día siguiente, tras una violenta carga de varios cuerpos policiales contra los manifestan-tes (pacíficos en ese momento) en torno a la Casa Blanca, Trump inició una procesión ro-deado de altos responsables de su administración, incluyendo al máximo responsable mili-tar de los ejércitos vestido de uniforme de campaña, y se presentó a un Photoshop con una biblia en la mano: «¿Es su biblia, señor presidente», preguntó una periodista; «es una bi-blia» respondió Trump (Washington Post, 2 de junio). Esta incitación a sus seguidores y la manipulación de la biblia inauguraron la semana de mayores protestas en Estados Unidos, que había de culminar con el día de más protestas (el 6 de junio).

Otro «momento Trump» es múltiple: son los continuos insultos dirigidos sin ninguna contención contra los manifestantes BLM. Reiterados insultos como «matones», «desgraciados», "anarquistas» "antifa» (estas dos expresiones utilizadas despectivamente), El 25 de junio tuiteó «Traición, Sedición, Insurrección» (y no era un señalamiento para el asalto al Capitolio que él iba a impulsar seis meses después). Eseverri (2011: 129) recuerda cómo se aceleraron las protestas de los jóvenes de las banlieues francesas cuando el ministro del interior Nicolas Sarkozy llamó "racaille de la societé» (escoria de la sociedad) a los jóvenes que se protestaban. Trump logró el mismo efecto con cada uno de sus tuits: a cada insulto, más manifestantes en las calles.

El cuarto «momento Trump» relevante para ver el papel que el $45^{\circ}$ presidente tuvo en la aceleración de las protestas es, paradójicamente, cuando se presentó como «el candidato (a la reelección) de la ley y el orden». Lo hizo a partir del día 16 de junio. Ya lo había hecho en 2016 olvidando que el contexto en que lo hizo Nixon en 1968 y el actual (de 2016 o de 2020) son radicalmente distintos; olvidando que ahora el presidente es él; y olvidando (o tal vez no) que la expresión «ley y orden» tenía (y tiene) un profundo tono racista. No en vano era uno de los pilares de la retórica de campaña de George Wallace en los años sesenta defendiendo la segregación racial (Nunberg, 2016). (Dejando aparte la paradoja de que Trump se presente como el garante de la «ley y el orden», cuando ha sido sometido a dos impeachment, ha defendido - y sigue defendiendo-fake news como la teoría conspiratoria de las «elecciones robadas», e incitara a la toma del Capitolio por sus seguidores el 6 de enero de 2021). Trump necesitaba que su (posibles) votantes blancos de los suburbios tuvieran miedo y a crear y potenciar ese miedo apostaron los medios de comunicación conservadores, con Fox News a la cabeza: «carnicería en las ciudades estadounidenses», "zona de guerra» fueron expresiones reiteradas en esos medios. Trump lo confirmaba diciendo que vivir en Baltimore, Oakland o Detroit era "como vivir en el infierno" (Washington Post, 27 junio) (para más detalles sobre esta campaña de creación de miedo véase Cachón 2021: 315 y ss.). En paralelo a la creación del miedo, Trump tenía que presentarse como un presidente enérgico. Y de paso provocar, más aún, a los manifestantes. Que respondieron a esta campaña de «ley y orden» alargando las manifestaciones. En este campo fueron muy significativos los ataques de Trump contra los manifestantes de 
Portland, Oregón (sobre todo en el mes de julio), o su visita a Kenosha el 1 de septiembre en plena recta final de la campaña electoral.

Ya se ha señalado que podría pensarse que las consecuencias de estas provocaciones de Trump son "consecuencias no queridas» de sus acciones. Para desenmascarar el auténtico objetivo de la lucha contra la drogas emprendida por Nixon en los años sesenta ha habido que esperar unos años hasta que John Ehrlichman, su jefe de política nacional, declaró: «La campaña de Nixon en 1968, y la Casa Blanca de Nixon después de eso, tenían dos enemigos: la izquierda pacifista y los negros (...) Sabíamos que no podíamos hacerlos ilegales por estar en contra de la guerra o por ser negros, pero al hacer que el público asociara a los hippies con la marihuana y a los negros con la heroína, y luego criminalizar a ambos de modo claro, podríamos perturbar esas comunidades. Podríamos arrestar a sus líderes, asaltar sus hogares, interrumpir sus reuniones y difamarlos noche tras noche en las noticias ¿Sabíamos que estábamos mintiendo sobre las drogas? Por supuesto que sí lo hicimos» (Baum,2016). Para decodificar la estrategia de Trump (sus tácticas) no ha habido que esperar tanto tiempo.

Kellyane Conway, una asesora clave de Trump y una de las que daban la cara por él en los momentos más delicados de su presidencia, tras intervenir en la Convención republicana, fue entrevistada en Fox News y lo dijo con claridad: «Cuanto más caos, anarquía, vanda-lismo y violencia reina, mejor será para la elección de quien es el mejor candidato en se-guridad pública y ley y orden» (Washington Post, 28 de agosto). Por eso tenía razón el en-tonces candidato demócrata Biden cuando dijo: «Donald Trump mira esta violencia y ve un salvavidas político» (New Yorker, 1 de septiembre). La respuesta de los manifestantes a las reiteradas provocaciones de Trump no fueron consecuencias no queridas sino objeti-vos deliberadamente buscados porque él y su equipo eran conscientes de que cuanto más caos, anarquía, vandalismo y violencia, mejor para la reelección de Trump de noviembre de 2020.

Junto a esto había que demostrar "dominio», una de las palabras favoritas de Trump en esos momentos. Y eso se tradujo en la mano dura de la policía contra los manifestantes, en la militarización de la policía y en el uso de la Guardia Nacional y otras agencias federales (como la policía de los Parques Nacionales) contra los manifestantes. ACLED (2020) ha mostrado como distintos cuerpos de policía utilizaron la fuerza de manera desproporcionada cuando intervenían en manifestaciones asociadas con el movimiento BLM, en relación con otros tipos de manifestaciones. Esto culminó en la «Operation Legend» que pretendía formalmente «sofocar los niveles inaceptables de violencia reciente en las ciudades de Estados Unidos» Pero se lanzó en julio, después de la fracasada intervención en Portland (donde la violencia desapareció en cuanto se retiraron las fuerzas federales), cuando ya las protestas estaban descendiendo y prácticamente no había protestas violentas. Su finalidad era más bien propagandística. El senador republicano Tom Cotton recomendó que la Administración «envíe las tropas» y que «no se dé cuartel a insurrectos, anarquistas, alborotadores y saqueadores» (New York Times, 3 de junio). De hecho, Trump 
intentó utilizar fuerzas militares contra los manifestantes activando la Insurrection Act de 1807 (sic), y solo se paró por la oposición de los militares (Atlantic, 3 de junio). Se trataba de «dominar el campo de batalla», una retórica de "guerra urbana» que se utilizó reiteradamente (Konaev y Brathwaite, 2020).

Tras las manifestaciones, una docena de ciudades llevaron a cabo evaluaciones de la actuación de las fuerzas policiales. El New York Times (20 de marzo 2021) sintetizaba los resultados: «Ciudad tras ciudad, la policía manejó mal las protestas de BLM». Los informes culpan repetidamente a los departamentos de policía de la escalada de violencia en lugar de contribuir a controlarla. Hay que recordar que desde hace décadas, los expertos en justicia penal han advertido que las tácticas policiales «guerreras» intensifican los conflictos en lugar de desactivarlos.

Además de las acciones de Trump y de la respuesta policial, otros «episodios» han contribuido a reactivar las protestas y lo han hecho de modo inmediato porque son chis-pas que provocan directamente otros estallidos. Este relanzamiento de las protestas se produce en primer lugar en las ciudades donde hay estos nuevos «George Floyd» locales (Williamson et al., 2018). En Cachón (2021: 223 y ss.) se recogen quince muertes de jóvenes negros a manos de la policía posteriores a la muerte de Floyd. Todos ellos han provocado protestas del movimiento BLM. Pero ha habido tres casos en que esas protestas han producido un relanzamiento significativo de las manifestaciones y también de las protestas violentas. La primera de ellas es la de Rayshard Brooks en Atlanta el día 12 de junio; la segundo ocurrió cuando se cumplían tres meses de la muerte de Floyd y las protestas declinaban; entonces un policía disparó siete tiros por la espalda contra Jacob Blake en Kenosha, Wisconsin, y esto produjo de modo inmediato violentas protestas en la ciudad y un relanzamiento de las manifestaciones BLM en todo el país en las semanas 13 y 14; un tercer momento de aumento significativos de las protestas a nivel de todo el país se produjo la semana siguiente cuando se conoció el video la muerte de Daniel Prude en Rochester, Nueva York, el 30 de marzo cuando estaba teniendo un ataque psicótico. Estos nue-vos «George Floyd» no son solo víctimas de la policía; porque otro de los aceleradores de las protestas fueron los muertos a manos de supremacistas blancos durante las protestas. El caso que tuvo más impacto fue el de Kyle Rittenhouse, un joven de 17 años seguidor de Trump que fue a Kenosha con su rifle AR-15 y mató a dos manifestantes. Kenosha pasó ser uno de los símbolos de las revueltas de 2020. Pero su caso es sólo una de las muchas acciones (con varios asesinatos) que supremacistas blancos seguidores de Trump llevaron a cabo en contra de los manifestantes y que no hicieron sino incrementar las protestas (véase Cachón: 330 y ss.).

Un cuarto tipo de aceleradores de las protestas fue la exoneración de los policías que mataron a Breonna Taylor. Como había ocurrido en Los Ángeles en 1992 cuando se exoneró a los cuatro policías que apalearon brutalmente de Rodney King (Winant, 1994) y como volvió a ocurrir cuando se dejó sin cargos al asesino de Trayvon Martin en 2013 (exoneración que dio lugar al nacimiento de \#BlackLivesMatter), la noticia de la exoneración de los po- 
licías que mataron a Breonna Taylor relanzó las protestas en todo Estados Unidos y Taylor pasó a ser una de los nombres más gritados en las manifestaciones y uno de los iconos de las protestas de 2020.

Se puede decir que todos estos "episodios», desde la muerte de Floyd a la exoneración de los policías que mataron a Taylor, pasando por las acciones de Trump y otros supremacistas blancos, activaron el "mecanismo social» de "perseverancia en la resistencia», tanto por parte del movimiento BLM como del componente antitrumpista de las protestas. Pero son varios elementos del contexto en que estas se producen los que dan la clave de la magnitud de las mismas.

\section{LOS CONTEXTOS DE LA MUERTE DE FLOYD QUE EXPLICAN LA MAGNITUD DE LA CONTESTACIÓN}

En los últimos años ha habido muchas muertes de jóvenes negros a manos de la policía, por disparos, estrangulamiento u otras formas de violencia, o por acciones de supremacistas blancos como la matanza de nueve afroamericanos en la Emanuel African Methodist Episcopal Church de Charleston en 2015. Pero solo la muerte de Floyd ha desatado una movilización sin precedentes en las luchas por la igualdad racial en Estados Unidos. Los "aceleradores» que se han señalado no explican por sí mismos la dimensión de las protestas. Solo un conjunto de "contextos» históricos determinados permiten comprender y explicar las dimensiones históricas de esa movilización colectiva por el impacto que el episodio de la muerte de Floyd (resultado del mecanismo «violencia (policial) sistémica contra los afroamericanos») y de los aceleradores han tenido sobre el mecanismo "persistencia en la resistencia». A continuación se señalan los aspectos más relevantes de los contextos que permiten comprender el significado de la dimensión de las protestas y su interrelación con los mecanismos sociales.

En el plano de la «larga duración», a un nivel estructural, el contexto (más) relevante es el «racismo sistémico» que existe en Estados Unidos contra los afroamericanos (y otras minorías). Como se ha señalado en otro lugar (Cachon, 2021: 89-90), «el "racismo sistémico" es un "sistema jerárquico fundacional, a gran escala e ineludible de la opresión racial estadounidense ideado y mantenido por blancos y dirigido contra las personas de color”; es una "realidad material, social e ideológica que está bien arraigada en las principales instituciones estadounidenses” (Feagin, 2006). Es algo fundacional porque está arraigado en la historia de Estados Unidos desde sus orígenes como nación, entonces adoptando la forma de esclavitud y luego la segregación del Jim Crow. Es a gran escala porque opera en todos los niveles sociales, desde las instituciones y las estructuras de poder hasta las relaciones sociales con los vecinos. El racismo sistémico es materialista y social porque implica un ordenamiento jerárquico y asimétrico de los grupos raciales respecto al poder y los recursos disponibles que persigue el mantenimiento de desigualdades materiales y de otros recur- 
sos a través de diferentes instituciones que garantizan una reproducción social favorable a los blancos. El racismo sistémico es también ideológico porque va acompañado de un discurso que legitima ese ordenamiento opresor y jerárquico a través de prejuicios, estereotipos e interpretaciones que racionalizan y justifican la opresión racial».

Ese racismo sistémico se manifiesta en todos los campos de la vida social (véase ibid.: 84108), desde la segregación residencial (el «American Apartheid» del que hablan Massey y Denton, 1993), a las desigualdades estructurales en el acceso a la educación, la discriminación en el mercado de trabajo o las desigualdades en acceso a servicios públicos como la salud (que la pandemia de la covid ha puesto en evidencia). El resultado es una brecha brutal de la riqueza entre blancos y negros: según la Reserva Federal (Bhutta et al., 2020) en 2019 las familias blancas tenían un patrimonio neto medio de 188.000 dóla-res; las negras de 24.100, ocho veces menor. Esta brecha de riqueza, fruto de la «inversión posesiva en blanquitud» (Lipsitz, 2018) y de las políticas federales en el New Deal que ayudaron a las familias blancas a lograr el sueño americano tras la Gran Depresión a consta de las minorías (Adelman, 2003), es un fundamento mayor de la reclamación de «reparaciones» debidas a los negros en Estados Unidos (Coates, 2014; Darity y Mullen, 2020). Una editorial del Washington Post (30 julio 2021) se hacía eco de la urgencia de actuar en este campo: «Estrechar la brecha de riqueza en Estados Unidos es importante. Estrechar la brecha de la riqueza racial es urgente». Pero más allá de la riqueza, el racismo sistémico impregna de discriminación prácticamente todos los aspectos de la vida social americana. Y las consecuencias se notan desde el nacimiento hasta la muerte: comienzan ya en la sala de partos, donde las mujeres negras mueren al dar a luz tres veces más que las blancas, y terminan con la muerte porque la esperanza de vida de las mujeres y hombres blancos es superior a las de sus pares negros. Todas estas desventajas raciales acumuladas en todos los aspectos de la vida social han sido uno de los contextos que han contribuido a la explosión de las protestas en 2021.

Para llevar a cabo el control racial de los afroamericanos en el campo penal, el «racismo sistémico» despliega sobre todo tres mecanismos. Para comprender cómo funciona ese control racial es útil la metáfora de la «jaula» (Young, 2000). No se entiende la jaula si se analizan los barrotes por separado porque ninguno de ellos por sí mismo garantiza la función de la jaula: mantener encerrado al pájaro. Solo si se comprende el conjunto de barrotes y la relación entre cada uno de ellos se puede entender por qué el pájaro no puede escapar de la jaula. Hay tres mecanismos relevantes. El primero es lo que Alexander (2012) ha llamado el «nuevo Jim Crow»: el sistema de «encarcelamiento masivo» que se puso en marcha con la llamada "guerra contra las drogas». Según Alexander (2012: 184): «En el sistema de encarcelamiento masivo, una amplia variedad de leyes, instituciones y prácticas (...) atrapan a los afroamericanos en una jaula virtual (y literal) (...). Lo más preocupante del nuevo sistema de castas raciales es que puede resultar más duradero que sus predecesores porque, como no se basa explícitamente en la raza, y por ello es más fácil de defender sobre bases aparentemente neutrales (...). Es mucho más conveniente imaginar que la mayoría de los jóvenes afroamericanos en áreas urbanas eligen libremente una 
Los contextos del linchamiento de George Floyd y los aceleradores de las ... | Lorenzo Cachón Rodríguez

vida delictiva que aceptar la posibilidad real de que sus vidas estuvieran estructuradas de tal manera que prácticamente garantizara su admisión temprana en un sistema desde el cual nunca pueden escapar». Floyd había caído en esta jaula y por eso la etiqueta de «ex preso» le perseguiría hasta su muerte. Otro de los mecanismos de control racial es la pena de muerte, esa «institución peculiar», como la ha llamado Garland (2010).

El tercero de esos mecanismos es el que llevó a la muerte de Floyd. Cazenave (2018) lo llama «Violencia policial y de los vigilantes» y que aquí hemos llamado «Violencia (policial) sistémica contra los afroamericanos». Ese ha sido el mecanismo causante de las protestas porque ha activado una respuesta de la histórica resistencia de los negros liderada por BLM y una respuesta de la resistencia antitrumpista. Que unos de los gritos más repetidos de las protestas fuera "defund the police» era una denuncia explícita del mecanismo que había sacado las multitudes a las calles. Un mecanismo que tiene pautas reconocibles de comportamiento que se producen en determinadas circunstancias y que tienden a producir efectos relevantes como es activar un mecanismo de resistencia y protesta. Examinando las muertes de negros a manos de la policía, Cazenave (2018: 24-25) ha mostrado nueve «pautas reconocibles»: 1) las víctimas tienden a ser jóvenes varones negros pobres desarmados a manos de policías blancos; 2) la policía actúa contra ellos con sesgo racial; 3) la policía y los negros tienden a dar versiones muy diferentes de lo ocurrido; 4) los policías son raramente perseguidos penalmente; 5) cuando los policías son acusados, raramente son condenados aunque existan pruebas claras contra ellos; 6) para evitar demandas civiles, las ciudades responsables de la policía ofrecen grandes cantidades de dinero a las familias como compensación; 7) hay un «código azul» (por el color del uniforme policial) de silencio dentro de la policía; 8) las protestas, tanto violentas como no violentas, que se producen tras las muertes de los negros a manos de la policía, «responden no a un incidente singular sino a una larga historia de un racismo percibido y a las malas conductas policiales»; 9) «No importa cuán indignantes sean los asesinatos y cuán intensa sea la crisis racial que provocan, tienden a no resultar en una reforma nacional en el sistema de justicia nacional.». Pero la importancia de las protestas tras la muerte de Floyd, pueden hacer que «esta vez sea diferente»: y así hay varios proyectos de reforma de distintos aspectos del sistema de justicia penal en el Congreso (véase Cachón 2021: 283 y ss.).

Este aspecto del racismo sistémico se manifiesta de modo cotidiano en las interacciones de los negros con la policía. En el discurso «He tenido un sueño» en la marcha de Washington de 1963 Martin Luther King Jr. mencionó más veces la violencia policial que la segregación racial. No es solo algo simbólico. Era el reconocimiento de la importancia que tenía entonces y sigue teniendo en la actualidad este mecanismo de control racial. Esto se refleja en que los hombres negros tienen 2,5 veces más probabilidades de morir a manos de la policía que los blancos (para las mujeres negras esa probabilidad es «solo" 1,4 veces mayor). Uno de cada 1.000 hombres negros puede esperar morir a manos de alguno de los 900.000 agentes de uno de los 18.000 cuerpos policiales distintos que hay en el país (The Marshall Project, 2020). No se trata de que haya «malos policías» o policías racistas (que haberlos, lo hay). «El racismo y los prejuicios tienen sus raíces en la propia institu- 
ción policial: hay pruebas considerables que indican que la policía usa con más frecuencia la fuerza contra las personas de color y revela que las fuerzas del orden se dirigen a las personas de color sin justificación (...) Es más probable que las unidades policiales militarizadas se desplieguen en comunidades de color; esta forma de vigilancia se asocia con más muertes por tiroteos policiales» (Michener, 2020). La defensa de Chauvin argumentó en el juicio en el que fue condenado por la muerte de Floyd que el agente estaba siguiendo las normas de su departamento de policía (algo que la jefa del departamento negó en su testimonio) (véase Cachón 2021: 193-195). Algunos departamentos de policía (como el de Mineápolis) están siendo investigados por el departamento de justicia por «pautas o prácticas» discriminatorias contra los negros.

Hay otros contextos relevantes "coyunturales» o de una duración media. El primero que hay que reseñar es la pandemia de la covid-19 y las consecuencias diferenciales que tuvo sobre la salud y la vida (y la muerte) de los diferentes grupos. Cuando Floyd murió se vivía en Estados Unidos casi el pico de muertes de lo que luego se supo era solo la primera fase de la covid-19 con enterramientos masivos en ciudades como Nueva York. Según el Center for Desease Control and Prevention, la probabilidad de contraer la covid-19 en los negros es 1,4 veces más que los blancos, la probabilidad de que sea grave y exija hospitalización es 3,7 veces más, y la probabilidad de morir por la covid-19 es 2,7 veces mayor. A ello se ha unido, cuando las vacunas contra la covid han estado disponibles, un menor nivel de vacunación de los afroamericanos. Y también han sufrido los más duros efectos sociales de la crisis económica. A partir de dos encuestas realizadas en el mes de julio, Arora (2020) ha mostrado cómo las consecuencias financieras negativas de la pandemia han contribuido a alimentar las protestas: el 52\% de los encuestados (el 69\% de los negros frente al 46\% de los blancos) informaron que se habían visto afectados económicamente al menos de alguna manera (de siete que se le presentaban) y estas personas han participado mucho más en las protestas de BLM dando razones como la justicia para Floyd y otras personas negras asesinadas, el apoyo a BLM, y la oposición a la brutalidad policial.

Las desigualdades sociales y la sensación de privación relativa es otro contexto relevante. Lo incluimos como coyuntural por el impacto específico de la aceleración de las desigualdades en el marco de la crisis ligada al covid19. Las revueltas de Harlem en 1943 inauguraron las protestas urbanas como respuesta a la frustración y la degradación racial relativa y esa volvería a ser la base de las protestas en Harlem y Brooklyn veinte años después (Cachón, 2021: 51). Ya había sido señalada como una de las causas del «Red Summer» de 1919 (Chicago Commission, 1922). El informe de Moyniham (1965) ponía el acento en los factores estructurales sociales y económicos para comprender la situación de los negros y en esa estela el Kerner Report interpretó las revueltas urbanas de los años sesenta como una muestra de que Estados Unidos se estaba moviendo «hacia dos sociedades, una blanca y otra negra, separadas y desiguales». Esas mismas causas estructurales ligadas a las desigualdades han sido puestas de relieve en varios informes en el Reino Unido (especialmente en el Scarman Report tras las revueltas de Brixton en 1981, y en el MacPheerson Report tras las de que se produjeron por la muerte de Stephen Lawrence en 1993) 
Los contextos del linchamiento de George Floyd y los aceleradores de las ... | Lorenzo Cachón Rodríguez

(Joly y Cachón, 2011). Las desigualdades han crecido en Estados Unidos de modo muy significativo desde mediados de los años 80 (Piketty, 2014) y la crisis de la pandemia de la covid las han acentuado aún más sobre todo en términos raciales. Uno de los aspectos en que esto se manifiesta es en la pérdida de empleos. La tasa de paro de los blancos aumentó en los primeros meses de 2020 desde el 3,5\% de enero hasta el 12,1\% en mayo, el mes de la muerte de Floyd; la tasa de paro de los negros en enero doblaba la de los blancos (era del 6,6\%) y en mayo alcanzó el 16,6\% (según el US Bureau of Labor Statistics). Olzak y Shanahan (1996) muestran como la contracción de las oportunidades laborales para las minorías creada por el desempleo tiende a aumentar significativamente la participación en disturbios raciales. También este contexto vino a facilitar y fomentar las protestas y la participación en ellas, sobre todo de los afroamericanos.

Otro contexto coyuntural relevante para comprender la magnitud de las protestas en la radicalización de los discursos políticos y sociales, en marco de la campaña electoral de noviembre de 2020. Aunque puede decirse que la dinámica de la tensión política en Estados Unidos se viene agudizando desde hace un par de décadas, la entrada de Trump en el campo político agudizó de modo extraordinario esas tensiones. Al día siguiente de la inauguración de su presidencia se inauguró «la resistencia» (Meyer y Tarrow, 2018). Esta radicalización de los discursos y de las posiciones había abierto un ciclo de contienda política que ha producido una resistencia antitrumpista que participaba en eventos de protestas de diferente carácter (Fisher y Jasny, 2019) y esto se convirtió en otro componente clave de las protestas. A medida que se acercaban las elecciones de noviembre y que los sondeos le daban como perdedor en las elecciones, esta dinámica antitrumpistas versus Trump se agudizó. Podría decirse que culminó en el asalto del Capitolio por parte de seguidores de Trump y supremacistas blancos el 6 de enero de 2021 (véase Cachón 2021: 330-382) frente a la victoria de «la resistencia» en las elecciones de noviembre de 2020. Esta persistencia de la resistencia permite ver en acción la «teoría del umbral del comportamiento colectivo» de Granovetter (1978), que sostiene que la decisión de un individuo de participar en el comportamiento colectivo a menudo depende de cuántos otros actores han decidido participar previamente.

A pesar de que la gran mayoría de las manifestaciones asociadas con BLM fueron pacíficas, una encuesta llevada a cabo en la segunda semana mostró que el $42 \%$ de los encuestados creía que «la mayoría de los manifestantes están tratando de incitar a la violencia o destruir propiedades» (FiveThirtyEight, 5 junio). Esta disparidad entre la realidad del levantamiento popular mayoritariamente pacífico y la percepción por parte de la opinión pública puede deberse a la radicalización de las posiciones y los discursos políticos, y a una cobertura desproporcionada de los actos violentos que habían producido en los medios de comunicación, sobre todo en Fox News. Un proxy de la tensión de la campaña electoral es el nivel de la participación en las elecciones del 3 de noviembre ya que nunca habían votado tantas personas en Estados Unidos: 66,8\%, un dato muy alto para el estándar estadounidense (en 2016 la participación también fue alta, pero se quedó en el 59,2\%). Un dato muy indicativo es que Trump obtuvo en 202011 millones de votos más que en 2016; 
Los contextos del linchamiento de George Floyd y los aceleradores de las ... | Lorenzo Cachón Rodríguez

pero perdió las elecciones porque sus 74 millones de votos quedaron lejos de los 81 millones obtenidos por Biden (15 millones más que Hillary Clinton en 2016).

Otro contexto coyuntural clave para entender la magnitud y extensión geográfica de las protestas desatadas por el mecanismo «persistencia de la resistencia» fue la existencia del movimiento Black Lives Matter (BLM) y el desarrollo de las redes sociales. BLM había nacido como hashtag tras la exoneración del asesino de Trayvon Martin en 2013 y se consolidó como movimiento tras la muerte de Michael Brown en Ferguson, Misuri, en 2014 (Day, 2015), aunque sus raíces vienen de mucho antes (Lebron, 2017). BLM ha estado presente en todas las movilizaciones contra la violencia policial desde 2014, movilizaciones que, en su mayoría, se han hecho bajo sus banderas (Nummi et al., 2019). Una de las razones por las que las protestas se han extendido por toda la geografía de Estados Unidos es el respaldo que reciben de esa organización (singular) que es BLM. Aunque BLM no está necesariamente dirigiendo cada protesta, proporciona materiales, orientación y un marco para los nuevos activistas (Buchanan et al., 2020). A ello se añade el papel de las redes que los activistas de BLM usan para compartir con rapidez los detalles de las protestas a una amplia audiencia con un efecto multiplicador. «BLM usa las redes sociales para convertir a la gente común en periodistas y movilizadores de protestas. Al no enfatizar demandas específicas de derechos políticos o civiles, BLM permite que muchas personas se identifiquen con su marco de derechos humanos, incluso aquellos que no apoyan a BLM» (Gause y Arora, 2021). Estas autoras han mostrado cómo un 20\% de los participantes en las protestas por la muerte de Floyd no apoyaban los objetivos de BLM, pero salieron a la calle a manifestarse porque estaban frustrados por la pandemia, con el gobierno y/o con otras injusticias no raciales. Se muestra así como las personas protestan cuando experimentan injusticias y tienen la oportunidad de expresar sus quejas (Klandermans, 2004) y, como ha mostrado McAdam (1999), históricamente, una de las condiciones necesarias para la insurgencia de los negros en Estados Unidos ha sido la existencia de una conciencia colectiva de injusticia y la creencia de que esos agravios pueden abordarse mediante la acción colectiva. Y BLM ha sido clave tanto en concienciar de la injusticia que representan las muertes de negros a manos de la policía como en estimular la movilización colectiva.

Numerosos estudios recientes sugieren que las redes sociales desempeñaron un papel fundamental en impulsar el crecimiento y la propagación de los movimientos sociales como el de BLM (Nummi et al., 2019). Porque las redes sociales brindan un espacio para que la difusión rápida de noticias políticas, para discutir cuestiones de actualidad, para dar forma a identidades colectivas, y, por supuesto, para movilizar a la ciudadanía contra injusticias sociales (Lee, 2020). Así es cómo BLM ha utilizado las redes sociales en las movilizaciones de 2020 (Bonilla y Tillery, 2020).

En las movilizaciones tras la muerte de Floyd han incidido también otros hechos que podríamos calificar como "contextos episódicos» y que son muestra del racismo sistémico a nivel cotidiano. En otro lugar (Cachón 2021: 139-158) se han señalado tres predictores racistas inmediatos de la muerte de Floyd: el asesinato del runner Ahmaud Arbery por su- 
premacistas blancos en Georgia en febrero; el de Breonna Taylor, muerta en su casa por disparos de la policía en Kentucky en marzo. Y un tercero que es un ejemplo del racismo que sufren los negros en Estados Unidos a nivel cotidiano y que ocurrió en el Central Park de Nueva York el mismo día de la muerte de Floyd. Es el caso Cooper versus Cooper. Una joven mujer blanca de nombre Cooper acusa falsamente a un joven afroamericano, también de nombre Cooper pero con quien no tiene ninguna relación de parentesco, de haberla amenazado (en el juicio se supo que también le acusó de intento de agresión sexual). Cuando Floyd murió, el video del enfrentamiento de los Cooper se había visto millones de veces en las redes sociales causando una gran rabia porque se repetía una pauta de falsas acusaciones de agresiones sexuales de hombres negros contra mujeres blancas (Henderson y Jefferson-Jones, 2020). El caso recordaba a los «Central Park Five», el caso de cinco jóvenes negros (y alguno de ellos latino) que fueron falsamente acusados de la violación de una joven blanca que estaba corriendo por el Central Park en 1989. Pasaron más de una década en la cárcel hasta que se pudo demostrar que ellos no habían sido los responsables. Trump jugó un papel relevante en este caso ya que publicó a toda plana un anuncio en la prensa pidiendo la reinstalación de la pena de muerte para que se pudiera aplicar a los cinco negros falsamente acusados. Cooper versus Cooper no terminó con el hombre negro muerto, pero otro hombre negro iba a morir ocho horas después e iban a explotar las mayores protestas de la historia en Estados Unidos.

\section{CONCLUSIONES}

Tras el linchamiento de George Floyd el 25 de mayo de 2020, se han producido en Estados Unidos la mayor movilización colectiva de la historia moderna, tanto por el número de manifestaciones, su duración y extensión por toda la geografía del país, como por el número de participantes y la diversidad de su composición racial: cerca de 6.000 manifestaciones en las tres primeras semanas desde la muerte de Floyd, y unas 4.000 más hasta fin de año; 683 manifestaciones el sábado 2 de junio; manifestaciones en las que han participado entre 15 y 26 millones de personas (entre el 6 y el 10\% de la población).

Cuando Floyd pagó una caja de cigarrillos con un billete falso de 20 dólares en una tienda de su barrio en Mineápolis un mecanismo de control racial (Cazenave, 2018) que hemos llamado «Violencia (policial) sistémica contra los afroamericanos» se puso en marcha y acabó con su vida. Ese mecanismo tiene pautas reconocibles de comportamiento de los policías blancos que tienden a producir efectos relevantes en otros actores, en el caso de Floyd su muerte por asfixia bajo la rodilla de un policía; en más en general reiteradas muertes de (sobre todo, jóvenes varones) negros desarmados a manos de la policía. La muerte de Floyd activó otro mecanismo de rechazo del racismo y de la violencia policial y la "persistencia de la resistencia» hizo explotar las protestas de modo inmediato. Pero eso no explica la magnitud que llegaron a tener porque ya había ocurrido varias veces en los últimos años y las protestas habían sido limitadas. Esta vez ha sido diferente. Y lo ha sido 
porque se han producido una serie de "episodios» que han actuado como aceleradores o reactivadores de las protestas, de una parte, y, de otra, porque se han producido en unos contextos determinados que han puesto el escenario «adecuado» para una movilización colectiva de carácter histórico.

Los «episodios» más relevantes por su fuerza de aceleración y agudización de las protestas han sido de cuatro tipos. En primer lugar, las respuestas del presidente Trump: amenazando con una expresión cuyo origen es de violencia contra los negros: «cuando empiezan los saqueos, comienzan los disparos»; llamando a sus seguidores a enfrentarse con los manifestantes; insultando a los manifestantes de modo reiterado desde su ametralladora de Twitter; y presentándose como el candidato de «la ley y el orden» y alentando el «dominio» de la "guerra urbana» que, según él, se estaba produciendo. Este primer acelerador fue muy efectivo dado el componente antitrampista de la "persistencia de la resistencia». En segundo lugar, la respuesta violenta y militarizada de la policía que resultó en un incremento de las manifestaciones y de la violencia en las mismas (como han reconocido algunos departamentos de policía a posteriori). Si estos «episodios» fueron claros aceleradores de las protestas, otros dos fueron reactivadores de las mismas. Y reactivaron sobre todo el componente más estrictamente BLM del mecanismo. Fueron las otras muertes (como la de Brooks en Atlanta) o heridos (como Blake en Kenosha) a manos de la policía o por las muertes producidas por supremacistas blancos seguidores de Trump (como Rittenhouse en Kenosha) que produjeron un incremento de las protestas cuando ya comenzaban a descender. El mismo papel reactivador de las protestas lo tuvo la exoneración de los policías que mataron a Breonna Taylor y que recuerda el inicio de las revueltas violentas de Los Ángeles cuando los cuatro policías que apalearon brutalmente a Rodney King fueron exonerados.

Pero la explicación no es comprensiva sin desvelar el papel de los aspectos relevantes del entorno, de los contextos, en que se producen el «episodio» inicial y los «episodios» posteriores, y su relación con los mecanismos sociales que vienen a potenciar. Se han diferenciado contextos relevantes en función de su «duración» (Braudel, 1968). En la «larga duración», en el nivel estructural, el más relevante es el «racismo sistémico» (Feagin, 2006), un racismo que en la sociedad estadounidense es fundacional (porque existe desde los mismos orígenes del país), a gran escala (porque se reproduce en todas las instituciones sociales, sea la educación, el mercado de trabajo, o en la salud y la vivienda), materialista y social (porque tiende a organizar jerárquicamente a las personas en función de su origen racial), e ideológico (porque construye un discurso que quiere legitimar esa opresión). Pero este «racismo sistémico» tiene aspectos que lo relacionan directamente con el mecanismo social «Violencia (policial) contra los afroamericanos»: es todo el entramado institucional de la «jaula» del sistema de (in)justicia racial en Estados Unidos. Y que se muestra, por ejemplo, en el hecho de que los negros duplican a los blancos en las probabilidades de morir a manos de la policía.

Otros contextos relevantes con «coyunturales», o de media duración. Es el caso de la pandemia del covid-19, de las desigualdades sociales y la sensación de privación relativa que 
la crisis económica y social ligada a la pandemia ha incrementado, la radicalización de los discursos políticos y sociales en el marco de la campaña electoral de noviembre de 2020, o la existencia del movimiento Black Lives Matter y el uso de las redes sociales para fomentar la movilización contra la violencia policial y por la justicia racial. Los dos últimos contextos están directamente ligados al mecanismo "persistencia de la resistencia» que es la pólvora que explotó en forma de protestas. El primero ligado sobre todo al componente antitrumpista y el segundo sobre todo al componente BLM.

Además, se ha considerado un contexto relevante calificable como «episódico» que muestra la acción cotidiana del racismo y que el mismo día en que Floyd iba a morir se produjo en el Central Park de Nueva York cuando una mujer blanca acusó falsamente a un hombre negro que querer agredirla. Las redes sociales estaban calientes de ira con este tema cuando Floyd comenzó a decir «No puedo respirar».

Estos contextos que muestran el fundamento del mecanismo «Violencia (policial) contra los afroamericanos» y los distintos «episodios» que fueron la chispa que activó la pólvora de la «resistencia en la resistencia», ayudan a comprender la magnitud histórica de las manifestaciones que tuvieron lugar tras la muerte de Floyd. Tenía razón su hija Gianna: «Mi papá ha cambiado el mundo».

Si este cambio tiene más consecuencias a partir de ahora depende en gran medida de dos cuestiones: de la influencia que las protestas tengan en las políticas, y de la persistencia de la movilización social por la justicia racial. Sobre la primera hay que recordar una consecuencia práctica que han tenido las manifestaciones: ayudaron a activar el voto a favor de la candidatura Biden-Harris y de los demócratas en general en las elecciones de noviembre porque sus planteamientos están más próximos a los de los manifestantes y por el componente antitrumpista de «la resistencia»; además, en los diversas consultas que se hicieron en varios estados el día de las elecciones se aprobaron reformas significativas de las normas que regulan el comportamiento policial; otra consecuencia es que las primeras medidas que adoptó el presidente Biden han expresado un fuerte compromiso con la justicia racial (véase Cachón, 2021: 387-402). Otras experiencias históricas muestran que las protestas influyen en las políticas públicas, como señaló Buttom (1978) tras las revueltas de Watts. Cuáles vayan a ser los efectos permanentes y las reformas substanciales que ayuden a reformar la policía y avanzar en la igualdad racial en Estados Unidos depende en gran medida de cómo se resuelvan las tensiones en un Congreso extraordinariamente dividido. Pero ya decía Frederick Douglas que «el poder no concede nada sin una demanda. Nunca lo hizo y nunca lo hará». Ahora sí se ha pedido y la mayor parte de las reformas cuentan con apoyo de la opinión pública (pero no del establishment republicano).

La segunda cuestión relevante es la persistencia de la movilización social por la justicia racial. Las manifestaciones prácticamente han cesado. El componente antitrumpista ha desaparecido (aunque subsista la amenaza de Trump y sus seguidores). La movilización adopta ahora otras formas. Pero su futuro depende en gran medida de cómo evolucione la 
base social del movimiento Black Lives Matter y de otros grupos que luchan a nivel local por la justicia racial y por la transformación de las instituciones ligadas al sistema de justicia penal (policía, prisiones, sistema penal y carcelario, regulación de armas, lucha contra las drogas). Porque estos movimientos pueden perder eficacia o perecer sin una base sostenible de activistas comprometidos (Bunnage, 2014). La resiliencia de los defensores de la justica racial será un factor clave en los próximos meses y años. Para Cazenave (2018: 254) «la cuestión no es si el movimiento (BLM) sobrevivirá, sino cómo y en qué forma» lo hará. Entonces sabremos si se hacen realidad las palabras de Gianna Floyd.

\section{REFERENCIAS BIBLIOGRÁFICAS}

Abdul-Jabbar, K. (2020): «Don't understand the protests? What you're seeing is people pushed to the edge», Los Angeles Times, 30 mayo.

ACLED (2020): Demonstrations \& Political Violence in America, septiembre.

Adelman, L. (2003): "A Long History of Racial Preferences - For Whites», en RACE. The Power of an Illusion, PBS.

Alexander, M. (2012): The New Jim Crow. Mass Incarceration in the Age of Colorblindness, Nueva York, The New Press.

Ancelovici, M. (2021): "Conceptualizing the context of collective action: an introduction», Social Movement Studies, 20(2): 125-138.

Arora, M. (2020): «How the coronavirus pandemic helped the Floyd protests become the biggest in U.S. history», Washington Post, 5 agosto.

Baum, D. (2016): «Legalize It All», Harper’s Magazine, abril.

Bhutta, N. et al. (2020): «Disparities in Wealth by Race and Ethnicity in the 2019», FED Notes, 28 September.

Blow, Ch. M. (2020): «Destructive Power of Despair», New York Times, 31 mayo.

Bobo, L. y V. L. Hutchings (1996): «Perceptions of Racial Group Competition: Extending Blumer's Theory of Group Position to a Multiracial Social Context», American Sociological Review, 61(6): 951-972.

Bonilla, T y A. Tillery (2020): «Which Identity Frames Boost Support for and Mobilization in the \#BlackLivesMatter Movement?», American Political Science Review, 114(4): 947-962. 
Braudel, F. (1968): La historia y las ciencias sociales, Madrid, Alianza.

Buchanan, L., Q. Bui y J. K. Patel (2020): «Black Lives Matter May Be the Largest Movement in U.S. History», New York Times, 3 julio.

Bunnage, L. (2014): «Social Movement Engagement over the Long Haul: Understanding Activist Retention», Sociology Compass, 8(4): 433-445.

Button, J. (1978): Black Violence: Political Impact of the 1960's Riots, Princeton, NJ, Princeton University Press.

Cachón, L. (2021): No puedo respirar. Anatomía de la revuelta contra el racismo tras el linchamiento de George Floyd, Barcelona, Hacer editorial.

Cazenave, N. (2018): Killing African Americans. Police and Vigilante Violence as a Racial Control Mechanism, Neeva York, Routledge.

Chenoweth, E. (2020): «Questions, Answers, and Some Cautionary Updates Regarding the 3.5\% Rule», Harvard University, Carr Center Discussion Paper 2020-5.

Chicago Commission on Race Relations (1922): The Negro in Chicago; a study of race relations and a race riot, <https://archive.org/details/negroinchicagost00chic/page/n12/ mode/2up>.

CIVIS (2020): Public Opinion Data on Black Lives Matter Police Reform, junio.

Coates, T.-N. (2014): «The Case for Reparations», The Atlantic, junio: 1-60.

Darity, W. y K. Mullen (2020): From Here to Equality: Reparations for Black Americans in the Twenty-First Century, Chapel Hill: University of North Carolina Press.

Day, E. (2015): «\#BlackLivesMatter: The Birth of a New Civil Right Movement», The Guardian, 19 julio.

Eseverri, C. (2011): «Enseñanzas de la "revuelta urbana” en las banlieues francesas», en L. Cachón (dir.), Inmigración y conflictos en Europa, Barcelona, Hacer editorial: 107-150.

Falleti, T. G. y J. F. Lynch (2009): "Context and Causal Mechanisms in Political Analysis», Comparative Political Studies, 42 (9): 1143-1166.

Feagin (2006): Systemic Racism: A Theory of Oppression, Nueva York, Routledge.

Feagin, J. y C. Feagin (1978): Discrimination American Style: Institutional Racism and Sexism, Englewood, NJ, Printice Hall. 
Fisher, D. y L. Jasny (2019): «Understanding Persistence in the Resistance», Sociological Forum, 34(S1): 1065-1089.

Garland, D. (2010): Peculiar Institution: America's Death Penalty in an Age of Abolition, Cambridge, MA, Belknap Press.

Gause, L. y M. Arora (2021): «Not all of last year's Black Lives Matter protesters supported Black Lives Matter», Washington Post, 2 de julio.

Granovetter, M. (1978): «Threshold models of collective behavior», American Journal of Sociology, 83:1420-1443.

Hedström, P, y P. Ylikoski (2010): «Causal Mechanisms in the Social Sciences», Annual Review of Sociology, 36: 49-67.

Hedstrom, P. y R. Swedberg (eds.) (1998): Social mechanisms: An analytical approach to social theory, Cambridge, UK, Cambridge University Press.

Henderson, T. y J. Jefferson-Jones (2020): «\#«LivingWhile-Black: Blackness as Nuisance», American University Law Review, 69 (3): 863-914.

Joly, D. y L. Cachón (2011): «La construcción de la multiculturalidad a partir del conflicto», en L. Cachón (dir.), Inmigración y conflictos en Europa, Barcelona, Hacer editorial: 47-105.

Klandermans, B. (2004): «Why Social Movements Come into Being and Why People Join Them», en J. Blau (ed.), The Blackwell Companion to Sociology, Blackwell, Malden, MA: 268-281.

Konaev M. y K. Brathwaite (2020): «U.S. officials are talking about urban warfare. Here’s what urban warfare really involves», Washington Post, 4 junio.

Lebron, Ch. (2017): The Making of the Black Lives Matter: A Brief History of the Idea, Nueva York, Oxford University Press.

Lee, S. (2020): «Social Media Use and Social Movements and Protests», The International Encyclopedia of Media Psychology, 1-6.

Lipsitz, G. (2018): The Possessive Investment in Whiteness. How White People Profit from Identity Politics, Filadelfia, Temple University Press.

Mahoney, J. (2001): «Beyond correlational analysis: Recent innovations in theory and method», Sociological Forum, 16(3): 575-593. 
Massey, D. y N. Denton (1993): American Apartheid: Segregation and the making of the underclass, Harvard Uni. Press, Cambridge.

McAdam, D. (1991): Political Process and the Development of Black Insurgency: 1930-1970, Chicago, University Chicago Press.

McAdam, D., S. Tarrow y Ch. Tilly (2005): Dinámica de la contienda política, Barcelona, Hacer editorial.

McAdam, D., S. Tarrow y Ch. Tilly (2008): «Methods for measuring mechanisms of contention», Qualitative Sociology, 31(3): 307-331.

Merton, R. K. (1964): Teoría y estructura sociales, México, Fondo de Cultura Económica.

Meyer, D. y S. Tarrow (2018): The Resistance: The Dawn of the Anti-Trump Opposition Movement, Nueva York, Oxford University Press.

Michener, M. (2020): George Floyd's killing was just the spark. Here's what really made the protests explode», Washington Post, 11 junio.

Morris, A. (1984): The Origins of the Civil Rights Movement, Nueva York, Simon \& Schuster.

Moynihan, D. (1965): The Negro family: The case for national action, Washington DC, U. S. Department of Labor.

Nummi, J., C. Jennings, y J. R. Feagin (2019): «\#BlackLivesMatter: Innovative Black Resistance», Sociological Forum, 34 (S1): 1042-1064.

Nunberg, G. (2016): «Is Trump’s Call For 'Law and Order’ A Coded Racial Message?», NPR, 28 julio.

Olzak, S. y S. Shanahan (1996): «Deprivation and Race Riots: An Extension of Spilerman's Analysis», Social Forces, 74(3): 931-961.

Pawson, R. (2000): «Middle-range realism», Archives Européennes de Sociologie, 41(2): 283325.

Piketty, Th. (2014): Capital in the Twenty-Fist Century, Harvard University Press, Cambridge.

Putnam, L., E. Chenoweth y J. Pressman (2020): «The Floyd protests are the broadest in U.S. history - and are spreading to white, smalltown America», Washington Post, 6 junio. 
Rubin, J. (2020): «How white supremacy infected Christianity and the Republican Party», Washington Post, 3 agosto.

Scarman, L. (1981): The Scarman Report: the Brixton Disorders 10-12 April 1981, Harmondsworth, Penguin.

Siméant-Germanos, J. (2021): «Conceptualizing contexts or contextualizing concepts? On some issues of the modeling of relational spaces in the study of collective action", Social Movement Studies, 20(2): 139-154.

Sprunt, B. (2020): "The History Behind "When the Looting Starts, the Shooting Starts"», $N P R, 29$ de mayo.

Tarrow, S. y D. Meyer (2018): «The Challenges of the Anti-Trump Movement», Partecipazione e Conflitto, 11(3): 614-645.

The Marshall Project (2020): «The legacy of racism in American policing», The System, n. ${ }^{\circ} 1$.

Tilly, Ch. (2001): «Mechanisms in political processes», Annual Review of Political Science, 4: 21-41.

Tilly, Ch. (2006): «Why and how history matters», en R. E. Goodin y C. Tilly (eds.), The Oxford Handbook of contextual analysis, Oxford, Oxford University Press: 417-437.

Tilly, Ch. y R. E. Goodin (2006): «It depends», en R. E. Goodin y C. Tilly (eds.), The Oxford Handbook of contextual analysis, Oxford, Oxford University Press: 3-32.

Williamson, V., K.-S. Trump y K. Levine Einstein (2018): «Black Lives Matter: Evidence that Police-Caused Deaths Predict Protest Activity», Perspectives on Politics, 16/2: 400-415.

Winant, H. (1994): Racial Conditions. Politics, Theory, Comparisons, Minnesota, University of Minnesota Press.

Young, I. (2000): Inclusion and Democracy, Nueva York, Oxford University Press. 